\title{
Centennial- to millennial-scale sea-level change during the Holocene and Last Interglacial periods
}

\author{
Robert E. Kopp', A. Dutton ${ }^{2}$ and A.E. Carlson ${ }^{3}$
}

\begin{abstract}
An increasing number of studies reveal regional or global sea-level instability during interglacial periods, belying a traditional assumption of stability. Sea level may have undergone multi-meter-scale variability during the Last Interglacial period, and decimeter-scale variability in the late Holocene.
\end{abstract}

The scientific community has traditionally considered sea level to be more variable during glacial periods, subject to abrupt millennial-scale changes in climate and glacial dynamics than during warm interglacial periods, thought to be characterized by comparatively stable sea levels. That paradigm is now shifting. Recent reconstructions suggest that sub-millennial, multimeter-scale oscillations in sea level occurred during the Last Interglacial period and that decimeter-scale variability occurred during the mid to late Holocene in both relativeand global mean sea level.

\section{Last Interglacial sea-level variability}

The stability of Last Interglacial sea level is still debated, with various reconstructions suggesting between one and four distinct global sea-level peaks (Dutton et al. 2015; Fig. 1). Various reconstructions of local or global mean sea level have interpreted as global mean sea-level oscillations in the order of one to several meters in magnitude, occurring over 1-2 ka (Blanchon et al.
2009; Kopp et al. 2013; Rohling et al. 2008; Thompson et al. 2011). Multiple sea-level peaks have been interpreted from the planktic $\delta^{18} \mathrm{O}$ records of the Red Sea (Rohling et al. 2008). However, the uncertain age constraints on marine sediment records make it challenging to assess rates on 1-2 ka timescales, and the age model for this reconstruction has been modified several times (e.g. Grant et al. 2012). Though the potential local sea-level oscillations seen in the Red Sea record are intriguing, similar oscillations seen in the Holocene portion of the Red Sea record are not considered to represent actual changes in global mean sea level, leaving the interpretation of this variability open to debate.

Other reconstructions with radiometric chronologies are primarily derived from fossil coral reefs that grew near the sea surface. Given the limited precision of dating techniques for the Last Interglacial period, the identification of centennial-scale variability may well remain elusive, but it should be possible to resolve millennial-scale changes. The challenge here lies more in the vertical uncertainty related to paleo-water depth of the corals, raising questions as to whether the apparent sea-level variability in some records may be due to variable paleo-water depths or changes in coral ecology rather than local sea level itself. This demands future work to incorporate a more rigorous assessment of coral assemblages and sedimentary features to interpret sea-level variations, along with the fundamental observations of changes in elevation and time recorded by fossil coral archives. However other sedimentary features, such as erosional or exposure surfaces in these reef sequences, seem to support multi-meterscale variability during the Last Interglacial period (Hearty et al. 2007). Despite the interpretation of multiple peaks in sea level at several fossil coral reef sites around the globe, the lack of a consensus in the number magnitude and timing of such oscillations between individual studies and sites complicates a definitive interpretation of a global

\section{Bahamas}

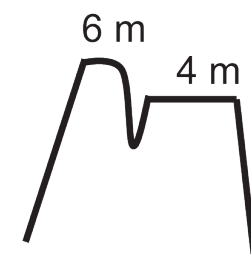

TWO PEAKS

Chen et al. (1991)

GSA Bulletin

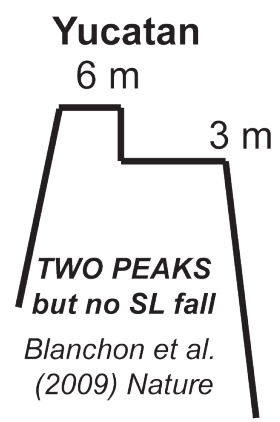

Western Australia

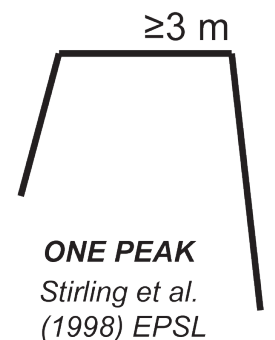

Global compilation

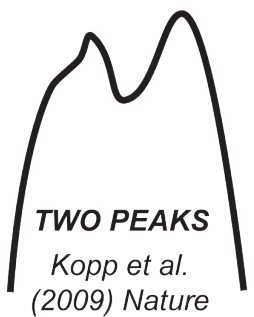

Barbados

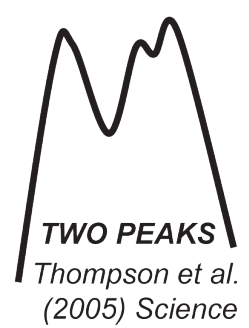

Bahamas

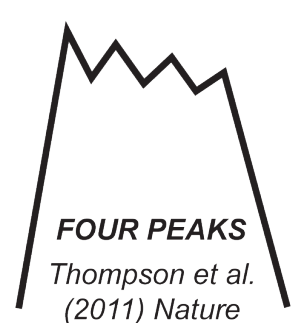

Global compilation

$6-9 \mathrm{~m}$

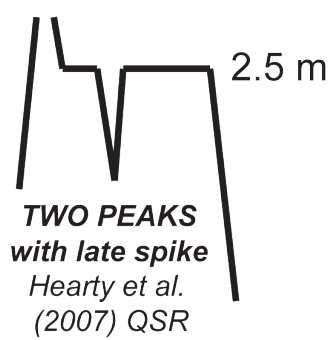

Western Australia

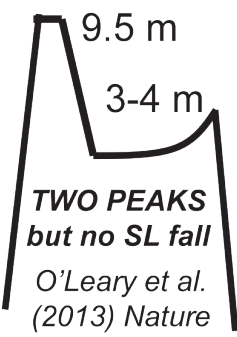

Red Sea

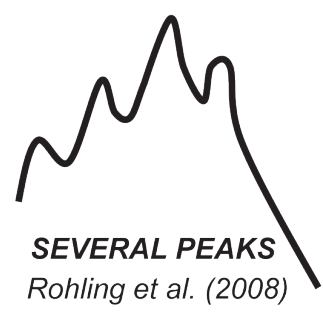

Nat. Geosci.

\section{Seychelles}

$7.6 \mathrm{~m}$

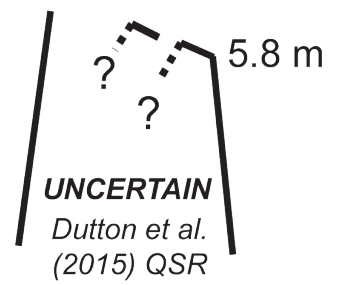




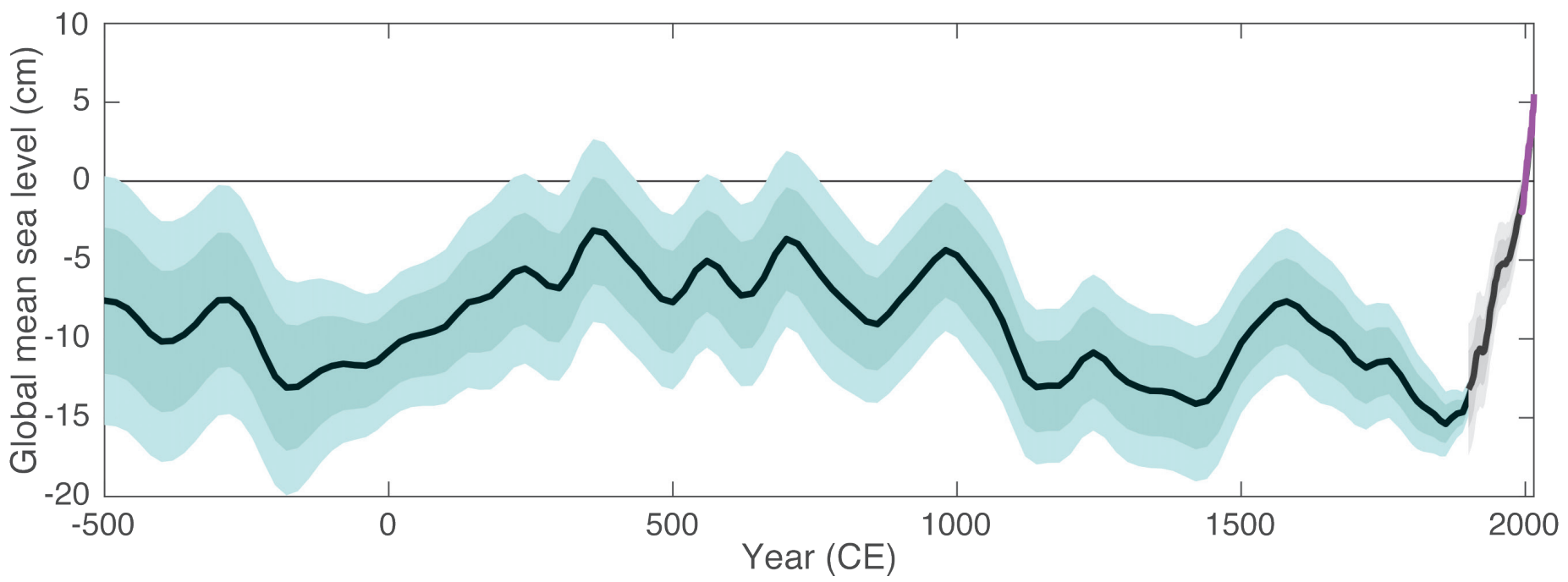

Figure 2: Global-mean sea level over the last $2.5 \mathrm{ka}$, based on the statistical synthesis of proxy data from Kopp et al. (2016; blue), the tide-gauge-based reconstruction of Hay et al. (2015; grey), and the satellite altimetry record (magenta). Heavy/light shaded regions are $67 \%$ and $95 \%$ credible intervals.

sea-level history. Nonetheless, numerous fossil reef sites clearly record at least two stratigraphically distinct generations of reef growth. These generations of reef growth often also display significant differences in their post-depositional diagenesis and coral taphonomy that would support the interpretation of a different post-depositional history before the reefs were exposed during the last glacial cycle (Blanchon et al. 2009; Dechnik et al. 2017).

While it is premature to provide a definitive answer regarding the number of sea-level peaks during the Last Interglacial or the rates of sea-level change associated with these millennial-scale sea-level oscillations, the body of evidence points towards a more variable sea-level history than in the Holocene. Of all contributors to sea-level change, only changes in ice sheets seem to have the potential to explain the inferred multi-meterscale changes. Existing ice-sheet evidence points towards a monotonic retreat of the Greenland ice sheet that can explain only a fraction of the overall sea-level highstand (Colville et al. 2011); data on the Antarctic ice sheet is inconclusive.

\section{Middle to Late Holocene sea-level variability}

In general, Holocene sea-level reconstructions have considerably less uncertainty both in time and the magnitude of changes, and hence are more likely to be able to resolve finer details in sea-level changes. Holocene sea-level proxy records are more abundant than in past interglacial stages, and considerable effort has gone into developing standardized databases that enable formal statistical analysis at both regional (e.g. Engelhart et al. 2015) and global (e.g. Kopp et al. 2016) scales.

Following the end of the final wastage of last ice-age ice sheets at $\sim 7 \mathrm{ka}$, Holocene sea-level rise slowed overall but continued to rise into the late Holocene, reflecting continued retreat of the Antarctic ice sheet (Ullman et al. 2016). In the late Holocene, the highest-precision proxies are derived from salt-marsh sediments and microfossil assemblages, which can yield decimeterscale vertical resolution and century- or sub-century-scale temporal resolution. Taking advantage of the compilation of wellstructured regional and global databases, Bayesian statistical methods have been used to both develop continuous records at individual locations and also estimate the overall spatio-temporal field of relative sea level at regional (e.g. Engelhart et al. 2015) and global scales (e.g. Kopp et al. 2016). Over the last two thousand years, a statistically identified common global sea-level signal exhibits decimeter-scale fluctuations that partially correlate with reconstructed global-mean surface temperature. Notably, a $\sim 0.2^{\circ} \mathrm{C}$ global-mean surface cooling over 1.0-0.6 ka (Marcott et al. 2013) coincides with a $0.2 \pm 0.2$ $\mathrm{mm} \mathrm{a}^{-1}$ global sea-level fall leading into the "Little Ice Age". The division of this sea-level fall between ocean thermal contraction and cryospheric growth is uncertain.

\section{Into the Anthropocene}

A significant global sea-level acceleration began in the late-19th century, with a global sea-level rise of $0.4 \pm 0.5 \mathrm{~mm}^{-1}$ over 1860 1900 CE (Kopp et al. 2016). At a regional scale, the timing of the sea-level acceleration varies broadly, with emergence above the rate of change due to glacial-isostatic adjustment occurring in the 19th century in some areas and the 20th century in others. In the 20th century, global sea level rose at a rate of about 1.4 $\pm 0.2 \mathrm{~mm} \mathrm{a}^{-1}$ (Hay et al. 2015; Kopp et al. 2016) - faster than during any century since at least $2.7 \mathrm{ka}$ (Fig. 2).

The end of the Little Ice Age and the nearsynchronous expansion of coal combustion in the 19th century make it challenging to disentangle natural and anthropogenic factors in late-19th and early-20th century sealevel rise. Using the relationship between global mean temperature and global-mean sea level over the last two millennia, Kopp et al. (2016) estimated that, without warming, 20th century global-mean sea level would extremely likely have been limited to -0.4 to $+0.8 \mathrm{~mm} \mathrm{a}^{-1}$ - leaving between 40 and $130 \%$ of the observed rise attributable the effects of twentieth-century global warming. The global-mean sea-level signal of warming emerged at the $95 \%$ probability level by 1970 CE.

The $\sim 3 \mathrm{~mm}^{-1}$ of global-mean sea-level rise since the early 1990s (Hay et al. 2015) has brought the world outside the realm of lateHolocene experience. With global-mean surface temperature now close to that of the Last Interglacial period (Hoffman et al. 2017), researchers have speculated that the world may be committed to long-term global mean sea-level rise comparable to the Last Interglacial period's 6-9 m peak elevation. Might we also see a return to the enigmatic multi-meter, millennial sea-level dynamism that may have characterized that stage?

\section{AFFILIATIONS}

IInstitute of Earth, Ocean and Atmospheric Sciences, Rutgers University, New Brunswick, USA ${ }^{2}$ Department of Geological Sciences, University of Florida, Gainesville, USA

${ }^{3}$ College of Earth, Ocean, and Atmospheric Sciences, Oregon State University, Corvallis, USA

\section{CONTACT}

Robert E. Kopp: robert.kopp@rutgers.edu

\section{REFERENCES}

Blanchon P et al. (2009) Nature 458: 881-884 Colville E et al. (2011) Science 333: 620-623 Dechnik B et al. (2017) Global Planet Change 149: 53-71 Dutton A et al. (2015) Science 349: aaa4019

Engelhart SE et al. (2015) Quat Sci Rev 113: 78-92 Grant KM et al. (2012) Nature 491: 744-747 Hay CC et al. (2015) Nature 517: 481-484 Hearty PF et al. (2007) Quat Sci Rev 26: 2090-2112 Hoffman JS et al. (2017) Science 355: 276-279 Kopp RD et al. (2013) Geophys J Int 193: 711-716 Kopp RE et al. (2016) PNAS 113: E1434-E1441 Marcott SA et al. (2013) Science 339: 1198-1201 Rohling EJ et al. (2008) Nat Geosci 1: 38-42 Thompson WG et al. (2011) Nat Geosci 4: 684-687 Ullman DJ et al. (2016) Quat Sci Rev 152: 49-59 